\title{
Quantitative Analysis of UDP-Glucuronosyltransferase Ugt1a and Ugt2b mRNA Expression in the Rat Liver and Small Intestine: Sex and Strain Differences ${ }^{\mathbb{}}$
}

\author{
Takaya Kutsukake, ${ }^{1}$ Yoichi Furukawa, ${ }^{1}$ Kyoko Ondo, Saki Gotoh, (DTatsuki Fukami, \\ and Miki Nakajima
}

\begin{abstract}
Drug Metabolism and Toxicology, Faculty of Pharmaceutical Sciences (T.K., Y.F., K.O., S.G., T.F., M.N.), and WPI Nano Life Science Institute (T.F., M.N.), Kanazawa University, Kakuma-machi, Kanazawa, Japan
\end{abstract}

Received June 22, 2018; accepted October 29, 2018

\begin{abstract}
UDP-glucuronosyltransferases (UGTs) catalyze the glucuronidation of numerous endogenous and exogenous compounds to facilitate their excretion from the body. Because rats are commonly used in nonclinical studies, information regarding UGT species differences between rats and humans would be helpful for understanding human pharmacokinetics. In this study, we determined the absolute mRNA expressions of Ugt isoforms in the liver and small intestine of male and female Sprague-Dawley, Fischer 344, and Wistar rats. The sum of the mRNA levels of Ugt isoforms expressed in the liver was significantly $(P<0.005)$ higher than that in the small intestine regardless of the strain and sex. Ugt2b mRNA levels represented approximately $80 \%$ of total Ugt
\end{abstract}

mRNA levels in the liver, whereas Ugt1a mRNA levels accounted for almost $90 \%$ in the small intestine. Ugt2b2 mRNA was specifically expressed in Wistar rat liver, resulting in 2-fold higher expression of total hepatic Ugt mRNA in Wistar rats than that in the other strains. Wistar rats showed prominently higher Ugt2b3 and Ugt2b8 mRNA levels in the small intestine than the other strains. The difference between sexes was remarkable with regard to hepatic Ugt1a10 in any of the strains, although slight differences between sexes were also observed in multiple Ugt isoforms. Taken together, this study revealed sex and strain differences in mRNA levels of rat Ugts. The data shown here would be useful for the selection of rat strains in nonclinical studies.

\section{Introduction}

UDP-glucuronosyltransferases (UGTs) are responsible for the glucuronidation of a wide range of structurally diverse endogenous and exogenous substances (Tukey and Strassburg, 2000; Mackenzie et al., 2005). UGTs conjugate glucuronic acid to substrates to increase their water solubility and enhance their excretion through bile and urine (Dutton, 1980); therefore, glucuronidation is generally considered to be a detoxification reaction. UGT activities significantly affect the pharmacokinetic and pharmacodynamic profiles and toxicities of drugs. In humans, $40 \%-70 \%$ of all clinical drugs are subjected to glucuronidation by UGTs (Wells et al., 2004). UGTs are widely distributed throughout the body and have been found in the intestines, kidney, brain, pancreas, and placenta; however, most UGTs are found in the liver, which is the primary detoxification organ (Strassburg et al., 2000; Collier et al., 2002; Izukawa et al., 2009; Knights et al., 2013).

In humans, 19 functional UGT isoforms comprise two families (UGT1A and UGT2) based on genetic similarity (Guillemette et al., 2010). The UGT1A gene consists of multiple unique first exons and common exons 2-5 (Gong et al., 2001). There are nine functional UGT1A isoforms (UGT1A1, UGT1A3, UGT1A4, UGT1A5, UGT1A6, UGT1A7, UGT1A8, UGT1A9, and UGT1A10). The UGT2 gene family

\footnotetext{
${ }^{1}$ T.K. and Y.F. contributed equally to this work.

https://doi.org/10.1124/dmd.118.083287.

S This article has supplemental material available at dmd.aspetjournals.org.
}

includes three UGT2A isoforms (UGT2A1, UGT2A2, and UGT2A3) and seven UGT2B isoforms (UGT2B4, UGT2B7, UGT2B10, UGT2B11, UGT2B15, UGT2B17, and UGT2B28) (Riedy et al., 2000; Remmel et al., 2008). Similar to UGT1A family members, UGT2A1 and UGT2A2 are encoded by differential first exons that are spliced to common exons 2-6 of a single gene (Mackenzie et al., 2005; Sneitz et al., 2009). UGT2A3 and UGT2B isoforms are encoded by unigenes.

Rats are commonly used in nonclinical drug development studies to investigate the pharmacokinetic profiles or toxicity of new chemical entities. Since Ugts exert a critical influence on drug pharmacokinetics, species differences in Ugt expression profiles between humans and rats should be elucidated. In rats, there are 18 functional Ugt isoforms that are classified into three subfamilies: Ugt1a, Ugt2a, and Ugt2b (Mackenzie and Rodbourn, 1990; Haque et al., 1991). The rat Ugtla gene cluster is located on chromosome $9 \mathrm{q} 35$ and consists of multiple unique first exons and common exons 2-5. There are eight Ugtla isoforms (Ugt1a1, Ugt1a2, Ugt1a3, Ugt1a5, Ugt1a6, Ugt1a7, Ugt1a8, and Ugt1a10) with two pseudogenes (Ugtla4 and Ugt1a9) (Emi et al., 1995). The rat $U g t 2$ gene family located on chromosome $14 q 21$ includes three members of the Ugt2a subfamily and seven members of the Ugt2b subfamily (Klaassen and Parkinson, 2001). Rat Ugt2a1 and Ugt2a2 are formed by alternative splicing of variable first exons and common exons 2-6, whereas the Ugt2a3 and Ugt2b subfamilies (Ugt2b1, Ugt2b2, Ugt2b3, Ugt2b6, Ugt2b8, Ugt2b12, and Ugt2b34) are encoded by unigenes (Emi et al., 1995; Mackenzie et al., 2005). Tissue distribution of rat Ugt1a and Ugt2b mRNA expression was previously reported 
(Shelby et al., 2003). However, a quantitative evaluation remains to be performed. Since the glucuronidation potential depends on the UGT isoforms expressed in tissues and their abundance, information about the absolute expression levels of individual Ugts in rat tissues would be useful in estimating the contribution of glucuronidation to pharmacokinetics or toxicity.

Glucuronidation occurs primarily in the liver, but it has become clear that glucuronidation in extrahepatic tissues has a significant impact on the pharmacokinetics and bioavailability of UGT substrates (Fisher et al., 2001). In fact, previous studies reported that rat intestinal UGT contributes to the first-pass effect (Xu et al., 2009; Furukawa et al., 2012). This study aimed to determine the absolute expression levels of rat $U g t \mathrm{mRNA}$ in the liver and small intestine and to clarify sex and strain differences in their expression levels among male and female SpragueDawley (SD), Fischer 344 (F344), and Wistar rats, which are all commonly used in nonclinical studies.

\section{Materials and Methods}

Materials. RNAiso Plus, a random hexamer, and SYBR Premix Ex Taq were purchased from Takara Bio (Shiga, Japan). ROX and ReverTra Ace were from Stratagene (La Jolla, CA) and Toyobo (Tokyo, Japan), respectively. Primers were commercially synthesized at Rikaken (Tokyo, Japan). All other reagents were of the highest grade commercially available.

Animals. Male and female (7-week-old) Sasco SD rats (140-230 g), F344 rats (110-140 g), and Wistar rats (150-230 g) were purchased from Japan SLC (Hamamatsu, Japan). The animals were housed in an institutional animal facility in a controlled environment $\left(25^{\circ} \mathrm{C}\right.$ temperature and a 12-hour light/dark cycle $)$ with access to food and water ad libitum. Rats were acclimatized for 3 days before use and maintained in accordance with the National Institutes of Health Guide for Animal Welfare of Japan, as approved by the Institutional Animal Care and Use Committee of Kanazawa University.

Total RNA from the Rat Liver and Small Intestine. Total RNA was isolated from 50-100 $\mathrm{mg}$ rat liver and small intestinal mucosa using RNAiso Plus according to the manufacturer's instructions (https://takara.co.kr/file/manual/pdf/ 9108_9109_e.v1301Da.pdf\#search=\%27RNAiso\%27). From the duodenum to upper jejunum were used as the small intestine, because UGT activities in these parts are relatively higher than those in the lower jejunum and ileum (Shiratani et al., 2008). The ratio of the band intensities of the $28 \mathrm{~S}$ and $18 \mathrm{~S}$ ribosomal RNAs was used to confirm the integrity of the extracted RNA.

Real-Time Reverse Transcription Polymerase Chain Reaction. cDNA was synthesized from $4 \mu \mathrm{g}$ total RNA extracted from the rat liver and small intestine using ReverTra Ace with a random hexamer. cDNA samples from each individual rat were pooled within groups (three rats per each strain and sex). A $1-\mu 1$ portion of the pooled cDNA was added to a polymerase chain reaction (PCR) mixture containing $10 \mathrm{pmol}$ of each primer (Supplemental Table 1), $12.5 \mu \mathrm{l}$ SYBR Premix Ex Taq solution, and $75 \mathrm{nM}$ ROX in a final volume of $25 \mu \mathrm{l}$. For Ugtla mRNAs, sense primers were set at the specific region in the exon of each isoform, and the antisense primer set at exon 2 was common for all Ugtla isoforms except for Ugt1a5 (Supplemental Table 1). Another antisense primer was designed for Ugtla5 because the amplification efficiency with the former antisense primer was low. For Ugt2b mRNAs, sense and antisense primers were designed at the specific regions within exon 1 and exon 2, respectively.

PCR conditions were as follows: after an initial denaturation at $94^{\circ} \mathrm{C}$ for 25 seconds, the amplification was performed by denaturation at $94^{\circ} \mathrm{C}$ for 7 seconds; the annealing temperature and extension time are provided in Supplemental Table 1 for 40 cycles. Real-time reverse transcription PCR was performed using an Mx3000P instrument with MxPro QPCR software (both from Stratagene). Amplified PCR products were monitored by measuring the increase in SYBR Green I fluorescence intensity. A calibration curve was constructed using known amounts of PCR product. The copy number was calculated for each sample based on the calibration curve. Specific amplification was confirmed by digestion of the PCR amplicon with the appropriate restriction enzymes as needed. The sum of the copy numbers of all Ugt isoforms was used to calculate the percentage of the expression level of each Ugt isoform.

Statistical Analyses. A three-factor analysis of variance model with factors for sex, strain, tissue, and their interactions was used to compare group means.
Further analyses involving either one-way analysis of variance (followed by the Tukey honest significant difference test for pairwise comparisons) or two-sample $t$ tests were performed when significant interactions were observed among the factors in the three-way model. $P<0.05$ was considered statistically significant.

\section{Results}

Absolute Expression Levels of Ugt1a mRNAs in the Rat Liver and Small Intestine. Absolute Ugtla mRNA levels in the rat liver and small intestine are shown in Supplemental Table 2 and visualized in Fig. 1A. Ugtla1 mRNA levels in the liver were 3- to 29-fold higher than those in the small intestine in any strain. Regardless of the sex, F344 rats and Wistar rats had the highest Ugtla1 level in the liver and small intestine, respectively. In SD and F344 rat livers as well as SD and Wistar rat small intestines, Ugtla1 mRNA was significantly higher in females than in males. In F344 rat intestines, Ugt1a1 mRNA was significantly higher in males than in females, and no sex difference was observed in Wistar rat livers. Ugt1a2 mRNA levels in the small intestine were 46- to 211-fold higher than that in the liver of any strain. The Ugt1a2 mRNA level was highest in F344 male rat small intestines. In SD and Wistar rat small intestines, Ugtla2 mRNA levels were significantly higher in females than in males. Higher expression in females was also observed for hepatic Ugt1a2 levels. An opposite difference between sexes was observed in F344 rat small intestines. Ugt1a3 mRNA levels were higher in the small intestine than in the liver in any strain. Hepatic Ugt1a3 mRNA levels were significantly higher in females than in males. Such sex differences were also observed in SD and Wistar rat intestines, whereas the opposite sex difference was observed in F344 rat small intestines. Ugt1 a5 mRNA levels were 16-fold higher in the liver than in the small intestine in any strain. A difference between sexes was observed in Ugtla5 levels in SD rat livers. In females, SD rats showed significantly higher hepatic Ugt1a5 levels than F344 and Wistar rats.

Ugtla6 mRNA levels in the small intestine were slightly higher than those in the liver in any strain. The largest difference was observed in female SD rats (2.7-fold). In both the liver and small intestine, Ugtla6 mRNA levels were highest in male Wistar rats, with a significant difference between sexes. Similar differences between sexes were observed in F344 rat livers and small intestines, but an opposite difference between sexes was observed in Ugt1a6 levels in SD rat small intestines. Ugtla7 mRNA levels in the small intestine were 13- to 34-fold higher than those in the liver of any strain. The level was highest in male Wistar rats, with a significant difference between sexes. Similar sex differences were observed in F344 rat small intestines and Wistar rat livers, but an opposite difference between sexes was observed in SD rat small intestines. Ugt1a8 mRNA was only detected in male Wistar rat livers at a very low level. In F344 and Wistar rats, Ugt1a10 mRNA in the liver was significantly higher in females than in males. The highest level was observed in female SD rats, whereas it was not detected in male SD rats. Ugt1a10 mRNA was not expressed in the small intestine in any strain.

\section{Absolute Expression Levels of Ugt2b mRNAs in the Rat Liver} and Small Intestine. Ugt $2 b$ mRNA levels in the rat liver and small intestine are shown in Supplemental Table 2 and visualized in Fig. 1B. Ugt2b1 mRNA was expressed in the liver but not in the small intestine. The highest level was observed in the liver of male Wistar rats. In SD and F344 rats, the Ugt2b1 mRNA level was significantly higher in females than in males, whereas an opposite difference between sexes was observed in Wistar rat livers. Ugt $2 \mathrm{~b} 2 \mathrm{mRNA}$ was highly expressed in Wistar rat livers, with a level 1.4-fold higher in males than in females. Trace levels of Ugt 2 b2 were detected in SD and F344 rat livers, with no difference between sexes. Ugt2b2 was not expressed in the rat small intestine. Ugt2b3 mRNA levels in the liver were higher than in the small intestine in any strain. Levels in SD and Wistar rat livers were significantly higher in males than in females. In the small intestine, 
A
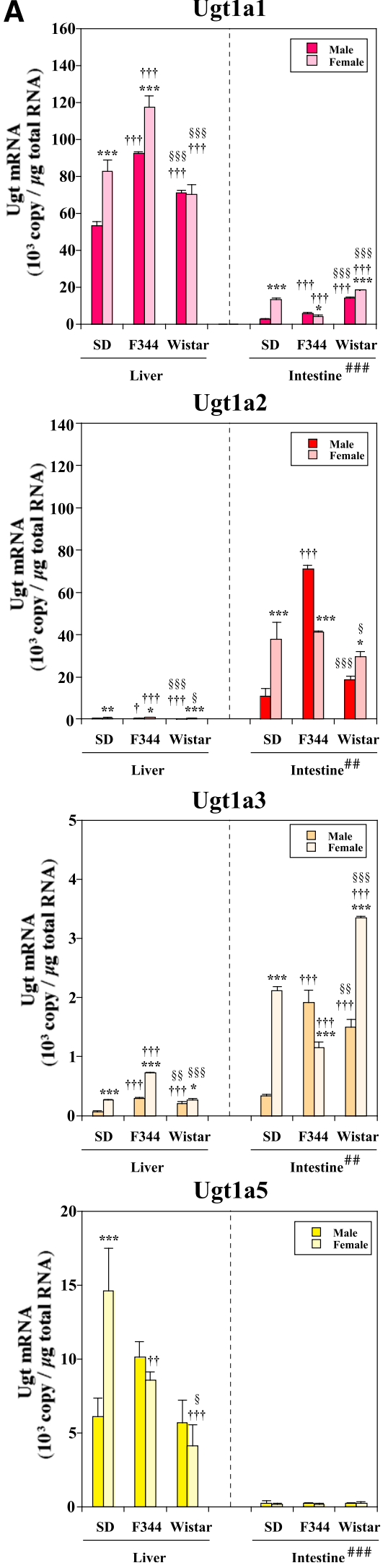
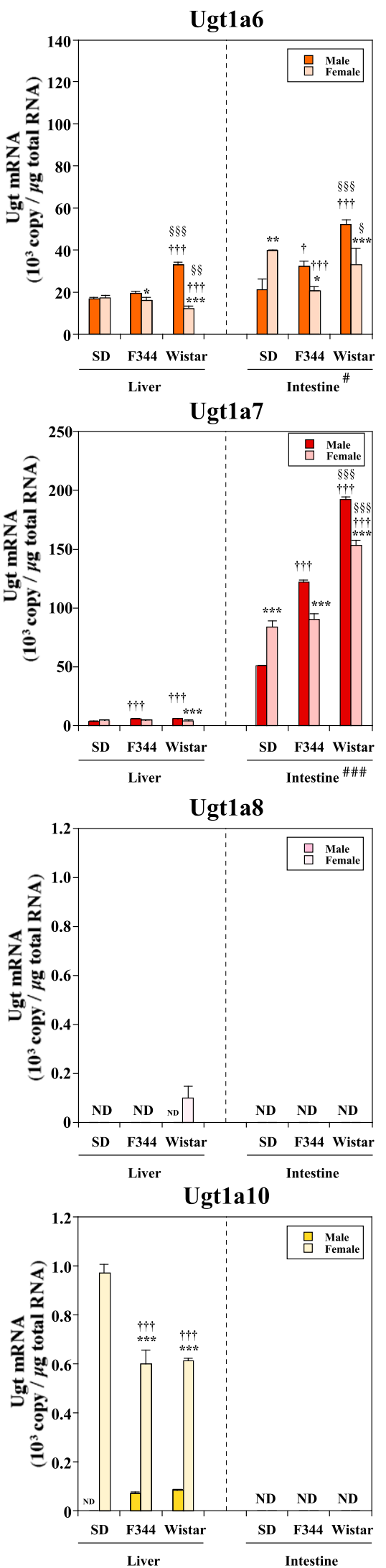

Fig. 1. Absolute quantification of Ugt mRNAs in the liver and small intestine from male and female SD, F344, and Wistar rats. (A) Ugt1a mRNA levels. (B) Ugt2b mRNA levels. The mRNA copy numbers were calculated from the standard curve of each Ugt. Each column represents the mean \pm S.D. of triplicate determinations. $* P<0.05$ $* * P<0.01 ; * * * P<0.001$ (compared with males); ${ }^{\dagger} P<0.05 ;{ }^{\dagger \dagger} P<0.01 ;{ }^{\dagger \dagger} P<0.001$ (compared with SD rats); ${ }^{\S} P<0.05 ;{ }^{\S \S} P<0.01 ;{ }^{\circledR \S \S} P<0.001$ (compared with F344 rats); ${ }^{\#} P<0.05 ;{ }^{\# \#} P<0.01 ;{ }^{\# \#} P<0.001$ (compared with liver). Gapdh, glyceraldehyde 3-phosphate dehydrogenase; ND, not detectable.
Ugt2b3 mRNA levels in Wistar rats were 15-fold higher than those in SD and F344 rats regardless of sex. The Ugt $2 \mathrm{~b} 6$ mRNA level was highest in the livers of male SD rats. The hepatic Ugt2b6 mRNA level in female SD rats was 4-fold lower than that in male SD rats. Levels in F344 and Wistar rats were comparable with those in female SD rats, with no difference between sexes. In the small intestine, a trace level of 
B
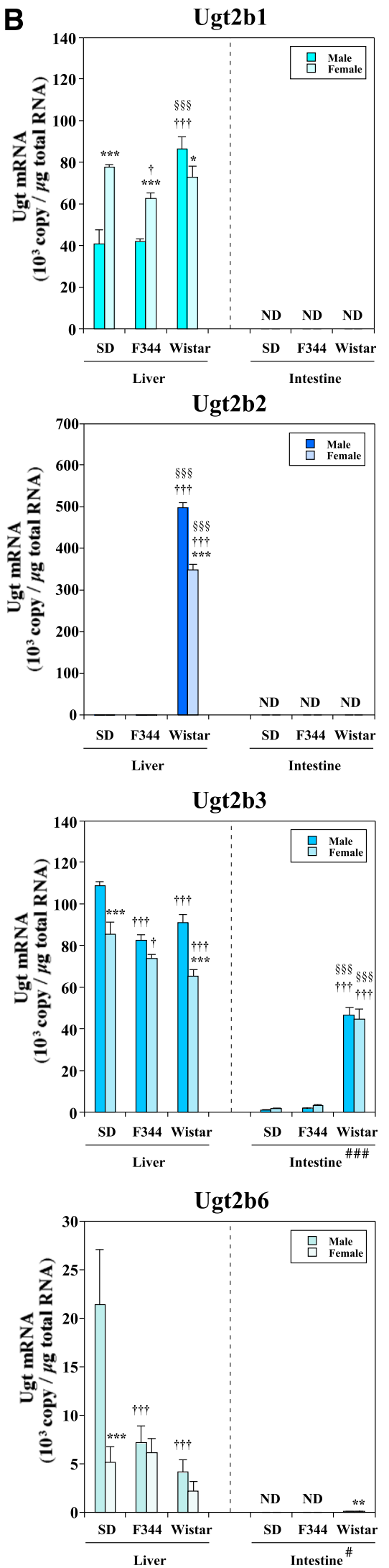

Ugt2b8
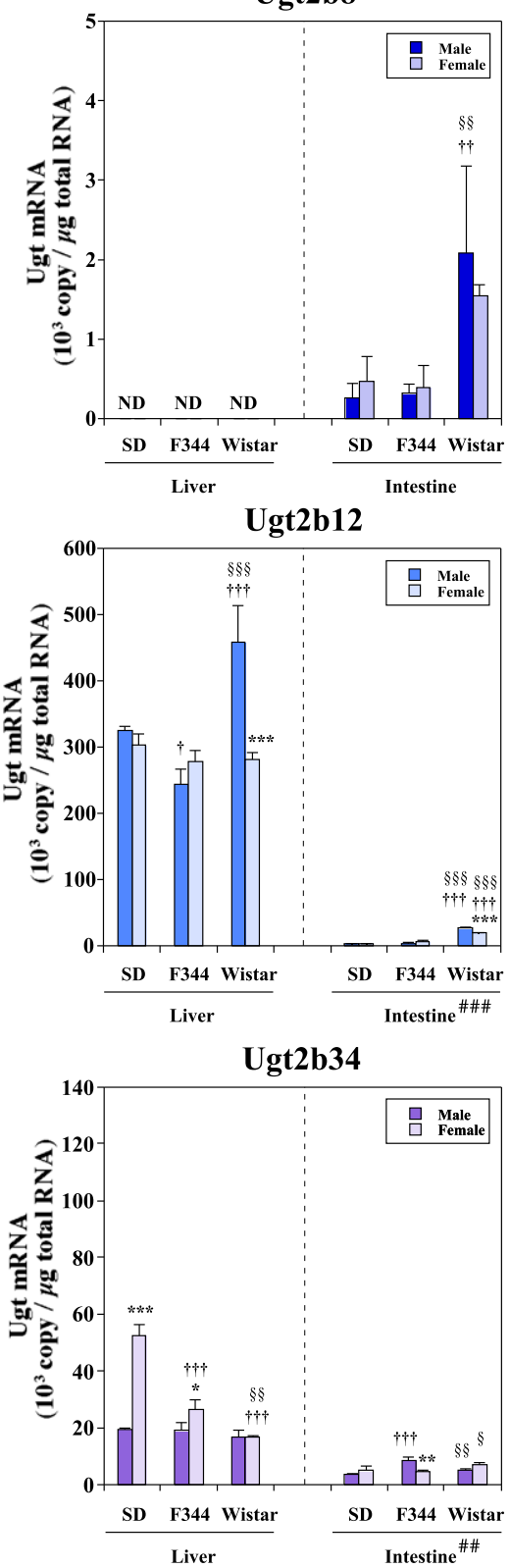

Fig. 1. Continued.

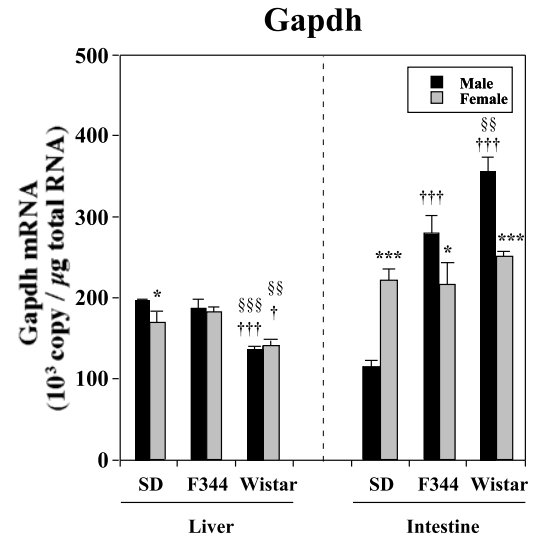

Ugt2b6 expression was detected in Wistar rats, with a difference between sexes (1.5-fold higher in males than females), but not in SD and F344 rats.
Ugt2b8 was expressed in the small intestine but not in the liver. The highest Ugt2b8 level was detected in Wistar rats. Ugt2b8 levels in SD and F344 rats were 3- to 7-fold lower than those in Wistar rats, but no 
difference between sexes was observed. Ugt2b12 mRNA levels in the liver were 14- to 116-fold higher than those in the small intestine. In Wistar rats, Ugt2b12 levels in the liver and small intestine were significantly higher in males than those in females. Meanwhile, no difference between sexes was observed in the other strains. Ugt2b34 mRNA levels were higher in the liver than those in the small intestine in any strain. Hepatic Ugt2b34 levels in males were equal in the three strains; in females, levels in SD rats were significantly higher than those in the other strains. In SD and F344 rats, levels were significantly higher in females than in males. In the small intestine, levels in females were equal in the three strains; in males, levels in F344 rats were higher than those in the other strains. In F344 rats, levels were significantly higher in males than in females.

Comparison of Ugt Expression Profiles in the Liver and Small Intestine of the Three Rat Strains. Figure 2A shows the sum of mRNA levels of individual Ugts in the liver and small intestine. The sums of all Ugts in the liver were 2.1- to 6.3-fold higher than those in the small intestine. Wistar male rats showed the highest levels in both the liver and small intestine. In the liver, the sums of all Ugts in Wistar rats were 2-fold higher than those in the other strains, which was due to abundant Ugt 2 b2 expression. In SD and F344 rat livers, the sums of all Ugts were slightly higher in females than in males. Meanwhile, in Wistar rats, the sums of all Ugts were higher in males than in females. In the small intestine, the sums of all Ugts were higher in Wistar rats than the other strains. In the SD rat small intestine, the sums of all Ugts were slightly higher in females than in males. Meanwhile, the opposite difference between sexes was observed in F344 and Wistar rats.

Percentages of mRNA levels of individual Ugts relative to total Ugt levels were calculated (Supplemental Table 3) and are visualized in Fig. 2B. Ugt $2 \mathrm{~b}$ accounted for approximately $80 \%$ of total Ugt levels in the liver. The most abundant isoform was Ugt $2 \mathrm{~b} 12$ (approximately $50 \%$ of total Ugts) in SD and F344 rat livers. In Wistar rat livers, Ugt2b2 (40\% of total Ugts) was the most abundant, followed by Ugt2b12 (approximately $35 \%$ of total Ugts). Ugt2b1, Ugt2b3, and Ugt1a1 accounted for approximately $10 \%$ of total Ugts. In the small intestines, Ugt1a accounted for approximately $90 \%$ of the total Ugt level. The most abundant isoform was Ugtla7 (50\% of total Ugts) regardless of strain and sex, followed by Ugt1a2 and Ugt1a6. Moderate expression of Ugt 2 b3 (14\% of total Ugts) was characteristic in the Wistar rat small intestine.

\section{Discussion}

Glucuronidation is a major conjugation pathway of a large variety of endogenous and xenobiotic compounds. UGTs play a significant role in the control of the pharmacokinetics, bioavailability, and toxicity of drugs. Expression profiles of human UGTs at mRNA and protein levels in several tissues have been well characterized (Strassburg et al., 1997; Tukey and Strassburg, 2001; Nakamura et al., 2008). As for rat Ugts, a previous article reported the tissue distribution (liver, kidney, lung, stomach, duodenum, jejunum, ileum, large intestine, cerebellum, and cerebral cortex) of Ugts at the mRNA level in SD rats by branched DNA signal amplification analysis (Shelby et al., 2003). Quantitative evaluation of rat Ugt expression remains to be performed. In this study, we sought to determine the absolute expression of Ugt1 and Ugt2b mRNA levels in the rat liver and small intestine by quantitative reverse transcription PCR to clarify sex and strain differences.

The sum of the expressions of all Ugts in the liver was significantly $(P<0.005)$ higher than that in the small intestine. This phenomenon was consistent with findings in human Ugts (Ohno and Nakajin, 2009; Court et al., 2012). In the rat liver, Ugt2b accounted for approximately $80 \%$ of the total Ugt mRNA level, which was consistent with the
A

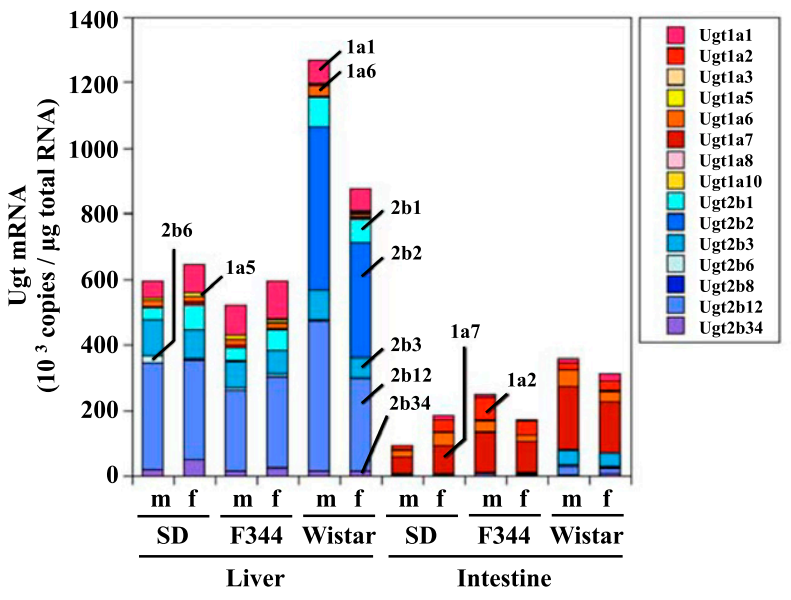

B

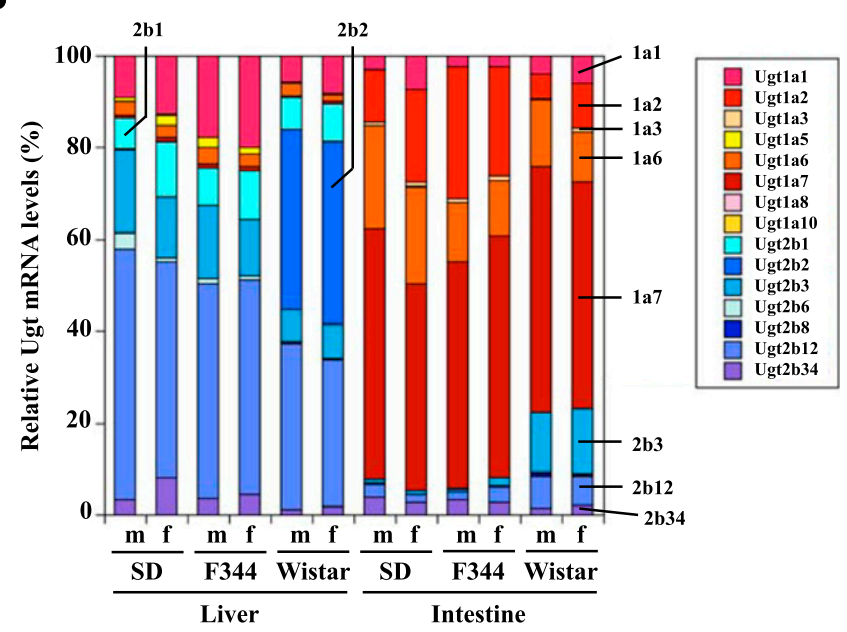

Fig. 2. Comparative evaluation of Ugt mRNA expression levels in the liver and small intestine from male and female SD, F344, and Wistar rats. (A) Sum of the absolute mRNA expression levels of Ugtla and Ugt2b in rats. (B) Percentage of each Ugt isoform mRNA level in the sum of all of the Ugt levels. f, female; m, male.

abundant expression of Ugt $2 \mathrm{~b}$ in the human liver (70\%-90\% of total Ugt mRNA) (Izukawa et al., 2009; Ohno and Nakajin., 2009; Court et al., 2012). In the rat small intestines, Ugtla accounted for approximately $90 \%$ of the total Ugt mRNA level. This observation was consistent with a previous report for human Ugt by Court et al. (2012) (approximately $90 \%$ of total Ugts), although Ohno and Nakajin (2009) reported that Ugtla accounts for $30 \%$ of total Ugts in the human small intestine. Based on a recent study, expression profiles of UGT1A and UGT2B in the liver and small intestine appear to be similar between humans and rats.

Particularly interesting findings of this study are the strain differences in Ugt expression profiles. Ugt2b2 is abundantly expressed in only Wistar rat livers, leading to 2-fold higher expression of total Ugts in the liver compared with the other strains. As for the strain differences, glucuronidations of androsterone and lithocholic acid, which are substrates of Ugt $2 \mathrm{~b} 2$, were previously detected in liver microsomes from SD rats but were hardly detected in those from F344 rats (Radominska et al., 1994). Richardson and Klaassen (2010) reported that the glucuronidation of triiodothyronine, which is a substrate of Ugt2b2, was detected in liver microsomes from Wistar rats but was hardly detected in those from F344 rats. According to these results, it has been recognized that Ugt2b2 is deficient in F344 rats (Haque et al., 1991). Our study showed that the Ugt2b2 mRNA level in F344 rat livers 
was extremely low, supporting the results of previous studies. In a previous study, Wistar rats were divided into two groups on the basis of hepatic microsomal glucuronidation of androsterone: those with high activity and those with low activity (Matsui and Hakozaki, 1979). The discontinuous variation was due to the genetic heterogeneity of Ugt (Beetstra et al., 1991). It would be plausible that the Wistar rats used in our study belong to the former group. When we measured hepatic Ugt2b2 levels in an additional eight individual Wistar rats (four males and four females) purchased from Charles River (Hino, Japan), the levels were comparable to those shown in Fig. 1B (data not shown). Thus, we could not find individual- and colony-dependent differences in Ugt2b2 expression in the 14 Wistar rats studied. Previous studies (Matsui and Hakozaki, 1979; Green et al., 1985) reported that discontinuous variation in androsterone glucuronidation was not observed in the SD strain. Shelby et al. (2003) reported substantial expression of Ugt2b2 mRNA in SD rat livers. Meanwhile, our study demonstrated that the Ugt2b2 mRNA level was extremely low in SD rat livers. As for the discrepancy, two reasons are considered. First, the probes to detect Ugt 2 b2 used in the study by Shelby et al. (2003) might react with other Ugt isoforms such as Ugt $2 \mathrm{~b} 3$ and Ugt $2 \mathrm{~b} 6$ because of their high homologies with Ugt2b2 (approximately 90\%). Supporting this suspicion, the tissue distributions of Ugt2b2, Ugt2b3, and Ugt2b6 were similar (Shelby et al., 2003). In this study, we carefully designed primers that can specifically detect only Ugt $2 \mathrm{~b} 2$ mRNA, and we confirmed that the amplicon was surely Ugt $2 \mathrm{~b} 2$ by cleavage with some restriction enzymes. Second, the glucuronidation of androsterone and lithocholic acid observed in SD rat microsomes might be due to other Ugt isoforms, because evaluation using recombinant rat Ugts was not sufficient enough in the past.

In addition to Ugt $2 \mathrm{~b} 2$, a distinct expression profile was observed in intestinal Ugt2b3. Ugt2b3 mRNA levels in the small intestine of Wistar rats were prominently higher than those in the other strains, resulting in higher expression of the total Ugt level in the small intestine of Wistar rats. Rat Ugt $2 \mathrm{~b} 3$ has been reported to catalyze the glucuronidation of aromatic primary amines (Irshaid and Tephly, 1987). Therefore, strain differences in the intestinal Ugt2b3 expression level may contribute to strain differences in the pharmacokinetics of such drugs. Taken together, we demonstrated that Ugt expression profiles in Wistar rats were different from those in other strains. This information may provide a hint for the selection of rat strains.

In humans, UGT1A7, UGT1A8, and UGT1A10 are expressed in the gastrointestinal tract but not in the liver (Tukey and Strassburg, 2001; Nakamura et al., 2008). Our study revealed that Ugt1a7 was highly expressed in the intestine in rats and slightly expressed (approximately $5 \%$ of total Ugts) in the liver. Meanwhile, Ugtla8 was hardly expressed in both the liver and intestine. In the study by Shelby et al. (2003), UGT1A8 mRNA was detected in the liver but at levels barely above the detection limit. Their probes for Ugtla8 in branched DNA assays might react with other Ugt isoforms showing high sequence similarity with Ugtla8. Rat Ugt1a10 was not expressed in the intestine but was expressed in the liver at a trace level $(0.1 \%-1 \%$ of total Ugts). These results demonstrated that the tissue distributions of UGT1A7, UGT1A8, and UGT1A10 were different between humans and rats. Previous studies reported that the tissue-specific distribution of human UGT1A7, UGT1A8, and UGT1A10 is regulated by transcription factors such as caudal-related homeodomain protein CDX2 and hepatocyte nuclear factor HNF4 $\alpha$ (Gregory et al., 2004; Mubarokah et al., 2018). Species differences in tissue distribution might be due to differences in the trans or cis factors between humans and rats. The mechanisms of tissuespecific expression of rat Ugts are an area for future study.

As for differences between sexes, hepatic Ugt1a10 levels were significantly higher in females than in males in all strains, although the copy number was much lower than other isoforms. In Wistar rats, the sum of the expression levels of hepatic Ugt2b isoforms was higher in males than in females. In F344 rats, the sum of the expression levels of intestinal Ugtla isoforms was higher in males than in females. Similar to the previous report by Shelby et al. (2003), hepatic Ugt1a5 and Ugt2b1 mRNA levels in SD rats were 2-fold higher in females than in males. Meanwhile, Emi et al. (1995) reported no remarkable differences between sexes in hepatic Ugt1a mRNA levels. Previous studies reported that sex hormones such as $17 \beta$-estradiol modulate some Ugt expression (Jeong et al., 2008; Chen et al., 2009). Therefore, the menstrual cycle may affect Ugt expression in females.

In conclusion, this is the first study to comprehensively quantify hepatic and intestinal mRNA levels of Ugt isoforms in SD, F344, and Wistar rats, which are commonly used for nonclinical studies. We provided basic information on species differences in hepatic and intestinal UGT expression between rats and humans as well as strain differences. Our results may be helpful for pharmaceutical scientists in choosing rat strains and sex for future studies.

\section{Authorship Contributions}

Participated in research design: Furukawa, Fukami, Nakajima.

Conducted experiments: Furukawa.

Contributed new reagents or analytic tools: Furukawa.

Performed data analysis: Kutsukake, Furukawa, Ondo.

Wrote or contributed to the writing of the manuscript: Kutsukake, Gotoh, Nakajima.

\section{References}

Beetstra JB, van Engelen JG, Karels P, van der Hoek HJ, de Jong M, Docter R, Krenning EP, Hennemann G, Brouwer A, and Visser TJ (1991) Thyroxine and 3,3',5-triiodothyronine are glucuronidated in rat liver by different uridine diphosphate-glucuronyltransferases. Endocrinology 128:741-746.

Chen H, Yang K, Choi S, Fischer JH, and Jeong H (2009) Up-regulation of UDPglucuronosyltransferase (UGT) $1 \mathrm{~A} 4$ by $17 \beta$-estradiol: a potential mechanism of increased lamotrigine elimination in pregnancy. Drug Metab Dispos 37:1841-1847.

Collier AC, Tingle MD, Paxton JW, Mitchell MD, and Keelan JA (2002) Metabolizing enzyme localization and activities in the first trimester human placenta: the effect of maternal and gestational age, smoking and alcohol consumption. Hum Reprod 17:2564-2572.

Court MH, Zhang X, Ding X, Yee KK, Hesse LM, and Finel M (2012) Quantitative distribution of mRNAs encoding the 19 human UDP-glucuronosyltransferase enzymes in 26 adult and 3 fetal tissues. Xenobiotica 42:266-277.

Dutton GJ (1980) Acceptor substrates of UDP glucuronosyltransferase and their assay, in Glucuronidation of Drugs and Other Compounds (Dutton GJ ed) pp 69-78, CRC Press, Boca Raton, FL.

Emi Y, Ikushiro S, and Iyanagi T (1995) Drug-responsive and tissue-specific alternative expression of multiple first exons in rat UDP-glucuronosyltransferase family 1 (UGT1) gene complex. J Biochem 117:392-399.

Fisher MB, Paine MF, Strelevitz TJ, and Wrighton SA (2001) The role of hepatic and extrahepatic UDP-glucuronosyltransferases in human drug metabolism. Drug Metab Rev 33:273-297.

Furukawa T, Nakamori F, Tetsuka K, Naritomi Y, Moriguchi H, Yamano K, Terashita S, and Teramura T (2012) Quantitative prediction of intestinal glucuronidation of drugs in rats using in vitro metabolic clearance data. Drug Metab Pharmacokinet 27:171-180.

Gong QH, Cho JW, Huang T, Potter C, Gholami N, Basu NK, Kubota S, Carvalho S, Pennington MW, Owens IS, et al. (2001) Thirteen UDPglucuronosyltransferase genes are encoded at the human UGT1 gene complex locus. Pharmacogenetics 11:357-368.

Green MD, Falany CN, Kirkpatrick RB, and Tephly TR (1985) Strain differences in purified rat hepatic $3 \alpha$-hydroxysteroid UDP-glucuronosyltransferase. Biochem J 230:403-409.

Gregory PA, Lewinsky RH, Gardner-Stephen DA, and Mackenzie PI (2004) Coordinate regulation of the human UDP-glucuronosyltransferase 1A8, 1A9, and 1A10 genes by hepatocyte nuclear factor $1 \alpha$ and the caudal-related homeodomain protein 2. Mol Pharmacol 65:953-963.

Guillemette C, Lévesque E, Harvey M, Bellemare J, and Menard V (2010) UGT genomic diversity: beyond gene duplication. Drug Metab Rev 42:24-44.

Haque SJ, Petersen DD, Nebert DW, and Mackenzie PI (1991) Isolation, sequence, and developmental expression of rat UGT2B2: the gene encoding a constitutive UDP glucuronosyltransferase that metabolizes etiocholanolone and androsterone. DNA Cell Biol 10:515-524.

Irshaid YM and Tephly TR (1987) Isolation and purification of two human liver UDP-glucuronosyltransferases. Mol Pharmacol 31:27-34.

Izukawa T, Nakajima M, Fujiwara R, Yamanaka H, Fukami T, Takamiya M, Aoki Y, Ikushiro S, Sakaki T, and Yokoi T (2009) Quantitative analysis of UDP-glucuronosyltransferase (UGT) 1A and UGT2B expression levels in human livers. Drug Metab Dispos 37:1759-1768.

Jeong H, Choi S, Song JW, Chen H, and Fischer JH (2008) Regulation of UDPglucuronosyltransferase (UGT) 1A1 by progesterone and its impact on labetalol elimination. Xenobiotica 38:62-75.

Klaassen CD and Parkinson A (2001) Biotransformation of xenobiotics, in the Casarett and Doull's toxicology, in The Basic Science of Poisons (Klaassen CD ed) pp 139-162, McGraw-Hill Companies, New York.

Knights KM, Rowland A, and Miners JO (2013) Renal drug metabolism in humans: the potential for drug-endobiotic interactions involving cytochrome P450 (CYP) and UDP-glucuronosyltransferase (UGT). Br J Clin Pharmacol 76:587-602. 
Mackenzie PI, Bock KW, Burchell B, Guillemette C, Ikushiro S, Iyanagi T, Miners JO, Owens IS, and Nebert DW (2005) Nomenclature update for the mammalian UDP glycosyltransferase (UGT) gene superfamily. Pharmacogenet Genomics 15:677-685.

Mackenzie PI and Rodbourn L (1990) Organization of the rat UDPglucuronosyltransferase, UDPGTr-2, gene and characterization of its promoter. J Biol Chem 265:11328-11332.

Matsui M and Hakozaki M (1979) Discontinuous variation in hepatic uridine diphosphate glucuronyltransferase toward androsterone in Wistar rats: a regulatory factor for in vivo metabolism of androsterone. Biochem Pharmacol 28:411-415.

Mubarokah N, Hulin JA, Mackenzie PI, McKinnon RA, Haines AZ, Hu DG, and Meech R (2018) Cooperative regulation of intestinal UDP-glucuronosyltransferases $1 \mathrm{~A} 8,-1 \mathrm{~A} 9$, and $1 \mathrm{~A} 10$ by $\mathrm{CDX} 2$ and $\mathrm{HNF} 4 \alpha$ is mediated by a novel composite regulatory element. Mol Pharmacol 93: 541-552.

Nakamura A, Nakajima M, Yamanaka H, Fujiwara R, and Yokoi T (2008) Expression of UGT1A and UGT2B mRNA in human normal tissues and various cell lines. Drug Metab Dispos 36: $1461-1464$.

Ohno S and Nakajin S (2009) Determination of mRNA expression of human UDPglucuronosyltransferases and application for localization in various human tissues by real-time reverse transcriptase-polymerase chain reaction. Drug Metab Dispos 37:32-40.

Radominska A, Little JM, Lester R, and Mackenzie PI (1994) Bile acid glucuronidation by rat liver microsomes and cDNA-expressed UDP-glucuronosyltransferases. Biochim Biophys Acta 1205: $75-82$.

Remmel RP, Zhou J, and Argikar UA (2008) UDP-glucuronosyltransferases, in Handbook of Drug Metabolism, 2nd ed (Pearson PG and Wienkers LC eds) pp 137-177, Informa Healthcare, New York.

Richardson TA and Klaassen CD (2010) Role of UDP-glucuronosyltransferase (UGT) 2 B2 in metabolism of triiodothyronine: effect of microsomal enzyme inducers in Sprague Dawley and UGT2B2-deficient Fischer 344 rats. Toxicol Sci 116:413-421.

Riedy M, Wang JY, Miller AP, Buckler A, Hall J, and Guida M (2000) Genomic organization of the UGT2b gene cluster on human chromosome 4q13. Pharmacogenetics 10:251-260.
Shelby MK, Cherrington NJ, Vansell NR, and Klaassen CD (2003) Tissue mRNA expression of the rat UDP-glucuronosyltransferase gene family. Drug Metab Dispos 31:326-333.

Shiratani H, Katoh M, Nakajima M, and Yokoi T (2008) Species differences in UDPglucuronosyltransferase activities in mice and rats. Drug Metab Dispos 36:1745-1752.

Sneitz N, Court MH, Zhang X, Laajanen K, Yee KK, Dalton P, Ding X, and Finel M (2009) Human UDP-glucuronosyltransferase UGT2A2: cDNA construction, expression, and functional characterization in comparison with UGT2A1 and UGT2A3. Pharmacogenet Genomics 19:923-934.

Strassburg CP, Kneip S, Topp J, Obermayer-Straub P, Barut A, Tukey RH, and Manns MP (2000) Polymorphic gene regulation and interindividual variation of UDP-glucuronosyltransferase activity in human small intestine. J Biol Chem 275:36164-36171.

Strassburg CP, Oldhafer K, Manns MP, and Tukey RH (1997) Differential expression of the UGT1A locus in human liver, biliary, and gastric tissue: identification of UGT1A7 and UGT1A10 transcripts in extrahepatic tissue. Mol Pharmacol 52:212-220.

Tukey RH and Strassburg CP (2000) Human UDP-glucuronosyltransferases: metabolism, expression, and disease. Annu Rev Pharmacol Toxicol 40:581-616.

Tukey RH and Strassburg CP (2001) Genetic multiplicity of the human UDP-glucuronosyltransferases and regulation in the gastrointestinal tract. Mol Pharmacol 59:405-414.

Wells PG, Mackenzie PI, Chowdhury JR, Guillemette C, Gregory PA, Ishii Y, Hansen AJ, Kessler FK, Kim PM, Chowdhury NR, et al. (2004) Glucuronidation and the UDP-glucuronosyltransferases in health and disease. Drug Metab Dispos 32:281-290.

Xu H, Kulkarni KH, Singh R, Yang Z, Wang SW, Tam VH, and Hu M (2009) Disposition of naringenin via glucuronidation pathway is affected by compensating efflux transporters of hydrophilic glucuronides. Mol Pharm 6:1703-1715.

Address correspondence to: Dr. Miki Nakajima, Drug Metabolism and Toxicology, Faculty of Pharmaceutical Sciences, Kanazawa University, Kakuma-machi, Kanazawa 920-1192, Japan. E-mail: nmiki@p.kanazawa-u.ac.jp 